\title{
Canada's Employment Equity Acts and the Communications Industry: Effective Social Regulation in a Neo-Liberal Era
}

\author{
Audrey Wubbenhorst \\ Prof. John Shields \\ The Major Research Paper is submitted \\ in partial fulfillment of the requirements for the degree of \\ Master of Arts
}

Joint Graduate Program in Communication \& Culture

Ryerson University - York University

Toronto, Ontario, Canada

April 30, 2004 
Analyzing American and Canadian policy trends in the 1970s, Peter Nemetz, W.T. Stanbury and Fred Thompson traced a new phenomenon: as economic regulation waned, "social regulation" became increasingly commonplace during this period. Social regulation is defined as unlike direct or industry-specific intervention as it typically impacted a broad, cross-section of industries (Nemetz, Stanbury and Thompson, 1986: 580 ). Uncovering this shift, they highlight the creation of new regulatory regimes in areas previously unregulated such as environmental protection, legislation to ensure health and safety and "fairness' regulation (principally in the area of human rights)" (Nemetz, Stanbury and Thompson, 1986: 580).

Although endeavouring to regulate analogous issues, social regulation was implemented differently north and south of the border. Whereas American social regulation tended to be "public, contentious and combative," Canada's version of social regulation was grounded in discretion and flexibility (Nemetz, Stanbury and Thompson, 1986: 594-595). A comparison of both nations' legislation on pure food drug and cosmetics reveals this key difference: the U.S. based legislation provides eight pages of prescriptive counsel while the Canadian legislation is a half page of high-level advice (Nemetz, Stanbury and Thompson, 1986: 594). Clearly, the Canadian proclivity was for "broad legislative mandates conferring substantial discretionary authority on the regulators" (Nemetz, Stanbury and Thompson, 1986: 594). As social regulation emerged in the 1970s in both Canada and the U.S., a crucial difference was its underpinnings: American legislation in this era tended to be inelastic; Canadian legislation was more fluid and less dogmatic. 
Canada's Royal Commission on Equality and Employment drafted in the early 1980s and the two versions of the Employment Equity Act it later inspired can be understood within this shift towards social regulation as defined by Nementz et. al. To appreciate how Canadian corporations are now mandated to achieve progress towards employment equity, it is critical to its history, its incarnations and its impact on corporate Canada. Curiously, while there was a sizeable amount of quantitative and qualitative research endorsing legislated employment equity written prior to the initial Act, there is only a handful of academic research evaluating its success. Academic space devoted to employment equity has existed mainly as a sidebar in a more extensive analysis of other policies such as the key works of Judy Fudge, Anver Saloojee, Patricia McDermott and Annis May Timpson which appraise employment equity, but as a benchmark against which to compare to other policies such as child care and pay equity. Through a literature review of the primary and secondary documents, which respectively shaped and critiqued the Act's two manifestations as well as case studies of communications companies, I will show that this legislation - an example of social regulation in a neoliberal era - was particularly effective once an audit component was added.

\section{The Abella Report: The Definition of Equality in Employment Shifts Expands}

As Nemetz et. al. have articulated, one form of social regulation which clearly surfaced in the 1970s involved legislation on "fairness" in employment across industries (Nemetz, Stanbury and Thompson, 1986: 580). Drafted in the early 1980s, Judge Rosalie Abella's prescient Royal Commission on Equality in Employment was indicative of two simultaneous trends in Canada: the shifting composition of the labour force and an 
emergence of new group politics arguably solidified by the onset of social regulation in Canada: when the Canadian Charter of Rights and Freedoms was entrenched in Canada's Constitution. Essentially, it attempted to forge a middle path between economic and human rights imperatives - a balancing act that continues to permeate the policy it initiated and its regulation today. The Commission's objective was to ensure workforce equality was clearly aligned to economic realities: women and new Canadians represented the majority of new entrants into the workforce (Timpson, 2001: 97). Abella's terms of reference were simply put to "inquire into the most efficient, effective, and equitable means of promoting equal employment opportunities" but she reinterpreted them to look at the structures, processes and systems needed before deciding who should be held accountable for their implementation (Abella, 1984: I). Ambitious, the Commission cast its consultative net wide and received 274 written submissions, held 137 meetings across Canada, and sought advice from an additional 160 individuals. Its end result was a 270-page report that outlined 117 recommendations.

Referring to American policies initiated by the Civil Rights movement, the Report indicated an explicit concern with the perceived narrow scope of the term "affirmative action" and instead advocated for a broad understanding of workplace equality (McDermott, 1993: 97). Abella was uneasy that the words "affirmative action" triggered "intellectual resistance," adding "In such cases it is sometimes worth changing the language in order to allow the debate to unfold on a more reasonable level" (Abella, 1984: 7). Attempting to mitigate backlash, Abella coined a new phrase: "employment equity." Despite advocating for a new idiom, she argued that semantics were only minimally significant: "Ultimately, it matters little whether in Canada we call this process 
employment equity or affirmative action, so long as we understand that what we mean by both terms are employment practices designed to eliminate discriminatory barriers and to provide in a meaningful way equitable opportunities in employment" (Abella, 1984: 7). Many of those suggestions-including the one on terminology - were passed by the Progressive Conservative government as the 1986 Employment Equity Act and were later revised by the Liberal government in $1995^{1}$ as employment equity was legitimised as a tool for remedying previous workplace discrimination.

Due to Abella's compelling research indicating that their labour market experience revealed a recurring pattern of high unemployment, below average pay rates and a concentration in subordinate roles, four perceived high-risk groups were selected by the federal government as requiring legislation to eradicate workplace barriers. In initial meetings with CEOs of Crown Corporations, Abella concluded that because of the extensive resources needed to implement it, Crown corporations could temporarily be competitively disadvantaged if the federal government applied the legislation to them exclusively. Therefore, the Employment Equity Act required that all federally regulated employers take steps to eliminate systemic discrimination. Its purview included banking, transportation, communications and a handful of dissimilar companies categorized as "other sectors." At its inception in 1986, the first Employment Equity Act governed approximately ten percent of the Canadian workforce and advocated for redressing

\footnotetext{
'Although lauded as a seminal study on Canada's workforces, the Abella report was not without criticism. In an article in Canadian Women's Studies written in 1985, lawyer Carole Geller provides a critique of its "liberalist tendencies." Geller argues that employment equity as Abella outlined in her report sees the removal of systemic barriers as the means to an end but fails to move to the next step: that is a rigourous quota-based "fair share" model as adopted in the United States (Geller, 1985: 22).

${ }^{2}$ Employers covered under the Employment Equity Act were grouped according to Standard Industrial Classification as published by Statistics Canada in 1980.
} 
systemic discrimination of four designated groups: Aboriginal people, ${ }^{3}$ people with disabilities, ${ }^{4}$ visible minorities ${ }^{5}$ and women (McDermott, 1993: 96). ${ }^{6}$

The shift towards four designated groups is momentous as it indicates a more complex understanding of workplace discrimination as part of a labour market strategy broader than those previously considered in Canada. ${ }^{7}$ Prior to Abella's report, analysis of workforce composition tended to be group specific. For instance, the role of women working in mass media was analysed in the watershed Royal Commission on the Status of Women. The influential report, an example of feminist engagement with the federal state and often credited as the harbinger for the Canadian women's movement in the 1970s, argued that women were chiefly represented in low-end white-collar jobs in the service sectors of the economy (Bird, 1970: 59; Brodie, 1996: 42). As the farsighted Royal Commission had predicted: "Laws can give women equal rights on the job. Only a radical change in the attitudes of society can give them equal opportunities in

\footnotetext{
${ }^{3}$ The Employment Equity Act defines aboriginal people as persons who are Indians, Inuit or Metis.

${ }^{4}$ Persons with disabilities are defined as persons who have a longterm or recurring physical, sensory, psychiatric or learning impairment and who a) consider themselves to be disadvantaged in employment by reason of that impairment or b) believe that an employer or potential employer is likely to consider them to be disadvantaged in employment by reason of that impairment.

${ }^{5}$ Visible minorities are defined by the Act as persons - other than Aboriginal persons - who are non Caucasian in race or nonwhite in colour.

${ }^{6}$ As per the Employment Equity Act, "only those employees who identify themselves to an employer, or agree to be identified by an employer as aboriginal peoples, members of visible minorities or persons with disabilities are to be counted as members of those designated groups for the purposes of implementing employment equity."

${ }^{7} \mathrm{Still}$, it is worth noting that the four designated groups are not uncontroversial. It is frequently argued that a macro-analysis of the groups may mask varying levels of discrimination. For instance, academic Martin Loney posits that employment equity is the antithesis of its title and in reality, reinforces inequality. Positing that class - rather than identity - results in barriers to the labour force, Loney suggests that "blue collar white males or males who are unemployed count for little against the persecution faced by those however rich and influential who daily confront the disadvantages of their gender" (Loney, 1998: 161). According to Loney, wealthy "disadvantaged" or designated groups are treated more favourably than genuinely deprived individuals not in designated groups (Loney, 1998: 165). The scope of Loney's argument is narrow: he only concerns himself with two of the designated groups, women and visible minorities. Convincingly though, Loney does question the failure of Canadians to fall neatly into allotted categories suggesting that the legislation "targets the recent affluent Hong Kong immigrant equally with the impoverished seventh generation black Canadian in Nova Scotia" (Loney, 1998: 173).
} 
employment and promotion" (Bird, 1970: 90). The original and revised Employment Equity Acts exemplified a key change since Bird's Commission: while the Acts drew on literature on policies to promote Canadian women's employment opportunities like the Commission, they emerged within the context of broader discussions and debates about how to root out discrimination in the workplace. Abella's Report functions as a signpost for this turning point as the Employment Equity Acts it motivated tackled workplace discrimination based on race, gender and ability in one inclusive piece of legislation.

Despite its wide scope and broad definition of equality, the Act was deemed unsuccessful. Indicative of such criticism of the first Employment Equity Act, in the early 1990s Judy Rebick, President of the National Action Committee on the Status of Women and Phoebe-Jane Poole argued that the Employment Equity Act was ineffectual since it lacked a prescribed enforcement mechanism and recognizing its limitations advocated for explicit enforcement (Poole and Rebick, 1994: 341-367). Using the CBC as an example, the authors adduced that while women's overall workforce representation had improved very slightly, their rates of hiring and promotion had decelerated while termination rates had increased. At this sluggish rate, Poole and Rebick predicted it would take thirty-five years for women to represent $50 \%$ of the workforce (Poole and Rebick, 1994: 347). ${ }^{8}$ Echoing Rebick and Poole, in an article in Canadian Women's Studies written in 1985, Lorna Marsden, then a Professor of Sociology at the University of Toronto argued that the Abella Report represented a groundbreaking shift in for its ability to clearly articulate the barriers to advancement of the four designated groups in

\footnotetext{
${ }^{8}$ Interestingly, in 2000 (eleven years after Poole and Rebick's article), the representation of women in the workforce under the Employment Equity Act was only 43.7\% (HRDC, 2001: 43). It should also be noted, however, that women in Canada have one of the highest labour force participation rates in the world although their paid employment tends to be segmented into the into lower paying and more contingent forms of work (Wilson, forthcoming).
} 
the labour force. Reaction to Abella's Report was affirmative in that she was able to articulate an exigent need for government intervention to eliminate workplace discrimination. However, reviews of the government's ability to use the first Employment Equity Act as an effective regulatory tool to combat workplace inequality were poor.

\section{The Employment Equity Acts: Varying Degrees of Social Regulation}

Adopting Nemetz et. al's definition of "regulation" as synonymous with "government intervention," I would argue that the first Act and its successor are both clear examples of social regulation in that they attempted to create workplace fairness in many industries simultaneously but they did so using two different models (Nemetz, Stanbury and Thompson, 1986: 591). The first Act was criticized by Poole, Rebick and Marden because it was too passive; it required regulated companies to submit reports annually to the federal government outlining their progress towards employment equity who acted as a filing cabinet, allowing the markets (corporate Canada) to set the terms of their progress towards employment equity. The revised version enacted in 1995 still required corporations to file annual progress reports but included an audit component or a proactive enforcement model of negotiation between the regulated (legislated employers) and regulators (the Canadian Human Rights Commission (CHRC)) to ensure corporate compliance with the Act's objectives.

Positioned in the context of a lever to enhance the economic well-being of Canada by ensuring efficient human resource utilization rather than a special measure assisting the four designated groups, Bill C64, proposed in 1995, laid out clear, complementary 
roles for HRDC and the CHRC. In this working model, HRDC would publicize the legislation, research its impact and oversee the Federal Contractors Program. ${ }^{9}$ The CHRC's new accountability involved reviewing annual reports submitted by employers, conducting audits and reviewing compliance. Auditors' expectations included an extensive employee survey to determine where gaps existed, an employment systems review to uncover barriers in hiring, promotion and retention, and the subsequent removal of those barriers.

As of 1986 , the term "employment equity" was solidified into public policy but I would suggest only ten years later did it become embedded in Canada's corporate lexicon when the legislation changed from a model of inert regulation to a model of hands-on government intervention - not as dictatorial a model as advocated by Poole and Rebick but a policy that is flexible allowing negotiation between employers and regulators. Launching the new policy, the press release outlined both the retained goals and directional shift to the legislation:

This new Act brings about long-awaited changes to the Employment Equity Act of 1986. The new Act replaces the 1986 Act as well as certain provisions of the Financial Administration Act with a single and more comprehensive regime that governs both private and public sector employers under federal jurisdiction. It strengthens previous employment equity law by clarifying employers' responsibilities and giving the Canadian Human Rights Commission the authority to ensure compliance. The new legislation is progressive, fair and reasonable, and re-affirms the government's commitment to the principles of employment equity (HRDC, 1996: 1).

Before the policy was redrafted, no single government agency was accountable for enforcing the law. According to Carole Ann Reed, the legislation has been successful

\footnotetext{
${ }^{9}$ The Federal Contractors Program applies to Canadian organizations awarded over $\$ 200,000$ in federal contracts and 100 or more employees. The Program stipulates that because of the contract, they must demonstrate accordance with the Employment Equity Act.
} 
in persuading corporations to embrace employment equity: minimal corporate resistance was the result of each federally regulated employment equity plan being designed and governed by the individual employer. The first Act gave companies breathing space: each employer was accountable for demonstrating only a "good faith effort to achieve their goals, not for actually achieving them" (Reed, 1996: 48). For Reed, the good faith governance policy was simultaneously powerful and immaterial: it was affirmative because employment equity had been accepted conceptually but ineffective because the concept was not enforced.

Similarly, Janet Lum and A. Paul Williams ask whether or not the revised Act fulfills its promise to rectify the weaknesses of its predecessor by posing the rhetorical question: does it really have more teeth? (Lum and Williams, 2000: 194-211). Lum and Williams situate the new Act within its political context: an attenuating postwar state in favour of increasingly predominating market forces. Primarily this period can be characterized by its two main planks: the retraction of the federal government's responsibility for managing the social and economic well-being of Canada while fostering market advantages such as lower business costs and fewer regulatory complaints (Lum and Williams, 2000: 196). The Act though contains holdovers of Keynesian philosophy: the concept that the state should become involved to correct market failures and produce a more equitable society. One example of this is the audit component, which seems anachronistic in this era.

Another such example of the state's continued involvement is the requirement of the Minister of HRDC to report annually to Parliament on employment equity in the private sector. Companies governed by the Employment Equity Act submit an annual 
report to HRDC outlining their progress towards employment equity in both an annual statistical report and a narrative report outlining the representation of designated groups. Failure to do so may result in a $\$ 50,000$ fine. Quantitatively, corporate plans had to classify not only the total number of workers in each occupational category such as "Clerical," "Senior Clerical," "Professional" and "Middle and Other Managers," but also they had to identify the number of designated group members in each occupation and predict how many employment opportunities are forecasted within the next three years providing numerical goals to increase the number of designated group members in each occupation. HRDC and its predecessor Employment and Immigration Canada compiled these documents into their Annual Report which is useful in that it provides a competitive analysis of companies and an industry comparison. Available online and at some libraries, they provide a window for the public to scrutinize employers' abilities to meet their goals.

Companies are then rated based on six significant indicators:

1. Representation: how well the employer is doing in ensuring that its workforce adequately represents the communities in which it does business

2. Clustering: the degree to which designated group members are equitably represented across 14 occupational groups. A clustering analysis enables an employer to determine if designated group members occupy jobs similar to others in the company.

3. Salary gaps: Compares salaries of designated groups to others in the organization.

4. Hirings: Measures the recruitment of designated group members against their labour market availability.

5. Promotions: Analysis rate of promotion of designated group members. 
6. Terminations: Measures whether or not designated groups were adversely affected by termination activities (HRDC, 2002: 68).

In comparing over a decade of Annual Reports produced by HRDC, it becomes clear that employment equity as a concept is becoming increasingly grounded in neoliberal terms. The latest 2001 report for instance highlights "The Business Case" arguing that:

Canadian companies are recognising that to be profitable they must expand their customer base and hire the best candidates. Employers are seeking global markets that require a new set of skills and talents. Globalization is rapidly changing demographics in Canada, and, some employers are achieving success by integrating employment equity initiatives and pursuing ethno-culturally diverse markets (HRDC, 2001 17).

It is worth noting the seismic shift that has occurred as HRDC incorporates the business imperative for employment equity into its lexicon. The argument is that for Canada, the costs of implementing employment equity on a national scale not be prohibitive. The cost of continuing inaction will inevitably prove to be one that Canada could not afford.

\section{Regulating Employment Equity in the Communications Sector}

Representing the largest number of employees governed by the Act, communications was clearly viewed as an industry unlike transportation and banking due to its unique ability to support and endorse employment equity through its business practices. The broadcasting community in particular was considered to have a unique role in promoting employment equity via media outlets. Historically, assimilation is a two-way street: designated groups adapt themselves to Canada's mainstream, but also they redefine and enrich the mainstream by contributing something of their own. In the 
1991 Annual Report released by Employment and Immigration Canada, ${ }^{10}$ an example of this vision that communications would be simultaneously a champion and exemplar of the positive potential of employment equity was articulated:

Employers in the broadcasting industry continue to influence the general population toward employment equity "in action" by the presence of representative role models to the public. These include, but are not limited to, certain weekly programs and documentaries depicting the lives and experiences of designated groups. One such weekly program, Disability Network, was developed in Toronto by the Canadian Broadcasting Corporation and the Centre for Independent Living in Toronto Inc. (EIC, 2001: 11).

Employers too recognized the inimitable role they play as visible advocates of employment equity. In its 2001 report to HRDC, the Canadian Broadcasting Corporation (CBC) submitted an overview of one of their programs intended to reflect shifting Canadian demographics:

As the face of Canada continues to evolve, the $\mathrm{CBC}$ has increased the number of new voices representing Canada's diversity on its services. English Radio's 'New Voices' initiative has resulted in bringing 3000 new voices to air, presenting people and stories who sound different and who bring a different perspective on matters. This has served to enrich English Radio's programming and sharpen its reflection of the country and also resulted in broad outreach and recruitment for occasional, casual or freelance workers (CBC, 2001: 2).

Further indicating communications' advocacy role, for the past two years, the CRTC has also begun to require all licensees to submit annual diversity plans (Morrisette, 2004).

HRDC's Annual Reports shed light on the current state of employment equity in communications. By and large, the industry is representative of the Canadian population in terms of the designated groups with the exception of people with disabilities. Significant progress has been made for women. In 2000, women in communications

\footnotetext{
${ }^{10}$ Human Resources Development Canada (HRDC)'s predecessor.
} 
were earning $86.6 \%$ of men's salaries vs. $63.5 \%$ in banking, $74.4 \%$ in transportation. In 1991, the wage gap between men and women in the communications sector was $21 \%$ versus 13.3\% in 2000 (EIC, 1991:23). The overall representation of Aborginal people in communications rose significantly in 2000 from $0.2 \%$ in 2000 to $1.3 \%$ (or by approximately 50 Aboriginal people) while it plateaued in transportation and declined in banking (HRDC, 2001: 49). Although, Martin Loney suggests that "The Canadian employment equity industry has been notably loathe to undertake studies that might seek to measure precise program impacts or to disaggregate the experience of particular target groups," HRDC has indeed taken significant steps to analyse its impact (Loney, 1998:

173). Interestingly, Aboriginal women in communications earn the highest average salary in the workforce. Similar to other industries, visible minorities tend to be concentrated in professional occupations in the communications workforce. In terms of salaries the gap is narrowing for visible minority men but widening for visible minority women. Hirings of people with disabilities have risen significantly in communications to $1.0 \%$ (approximately 2100 employees) but is still far from its peak in 1993 of $1.7 \%$ (approximately 3500 employees) (HRDC, 2001: 55).

Figure 1: Distribution of People with Disabilities Across Industries in 2000"1

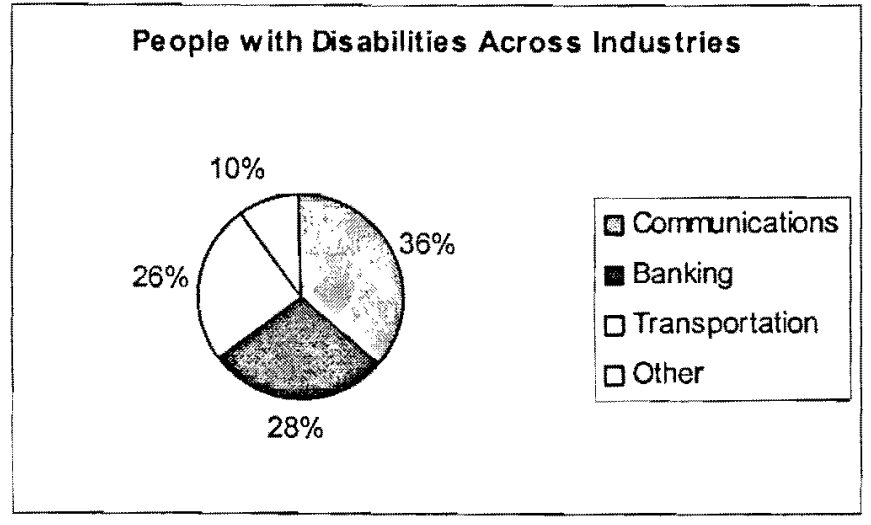

11 This chart is compiled based on data released by HRDC in the 2001 Annual Report (page 55). 
Some possibilities could explain this peak and subsequent decline: employers argue that people with disabilities are becoming less inclined to self-identify as a disabled person because of the fear of the adverse impact it would have on their employment opportunities (Morrisette, 2004). Another explanation could be that all the gains were made in the early 1990s and that since then there has been a slight erosion. It should be noted though that the majority - well over one third - of people with disabilities in the Canadian workforce governed by employment equity are in communications (see Figure 1). This large share of the population could be attributed to the fact that many of the companies studies have focused on increasing the accessibility of their office buildings as is clear from the following case studies. As communications companies tend to be based in a few locations - rather than many branches as in banking - making workplaces accessible likely requires fewer resources as this industry tends to own less properties than financial services. Given the much-trumpeted phenomenon of the impeding aging workforce, serious attention will need to be paid to this group across all industries.

From 1986-1996, like all regulated corporations, communications companies were required to file an annual report with the federal government. In addition to statistics in terms of the distribution of designated groups in various jobs, section 18 of the Employment Equity Act requires employers to include a narrative report in their annual submission "describing 9a) the measures taken by the employer during the reporting period to implement employment equity and the results achieved and $9 \mathrm{~b}$ ) the consultations between the employer and its employee representatives during the reporting period concerning the implementation of employment equity" (Statutes of Canada, 1996: Chapter 44). This report was written by an internal employee and submitted via the mail 
to Ottawa. An example of the self-regulation model in practice, no questions were asked of the report and consequently, it was viewed as a public relations obligation. As Abella had forecasted: "A requirement of public reporting may result in public pressure on a company to revise its systems but it is unrealistic to rely on public opinion as an effective monitoring agent. It results in a speculative and scattered approach and creates the perception, in the absence of enforcement, that the issue is deserving only of casual attention" (Abella, 1984: 195).

Since the first year communications companies had to file such reports, their industry has grown exponentially and so has the number of employees they report on (see Table 1). In 2002 , the communications industry represented $33.2 \%$ of the total workforce covered by the Employment Equity Act, followed by banking at $30.8 \%$ and transportation at $28.5 \%$ (HRDC, 2004: 2). As is clear from the chart below, the number of employees in communications has risen faster than banking or transportation. As of the 2001 report produced by HRDC, over 13,000 new employees had joined the communications sector in 2000 (HRDC, 2001: 39).

Table 1: Number of Employees and Employers by Sector ${ }^{12}$

\begin{tabular}{|l|r|r|r|r|r|r|r|r|}
\hline & \multicolumn{7}{|l|}{ Employers } & \multicolumn{2}{l|}{ Employees } \\
\cline { 2 - 8 } Sector & $\mathbf{1 9 8 7}$ & $\mathbf{1 9 9 9}$ & $\mathbf{2 0 0 0}$ & Difference 87-00 & $\mathbf{1 9 8 7}$ & $\mathbf{1 9 9 9}$ & $\mathbf{2 0 0 0}$ Difference 87-00 \\
\hline Banking & 23 & 21 & 21 & $-8.7 \%$ & 169632 & 174760 & 172447 & $1.7 \%$ \\
\hline Trans. & 208 & 173 & 232 & $11.5 \%$ & 203207 & 164513 & 177101 & $-12.8 \%$ \\
\hline Comm. & 90 & 94 & 91 & $1.1 \%$ & 179247 & 197960 & 211448 & $18.0 \%$ \\
\hline Other & 52 & 48 & 50 & $-3.8 \%$ & 43331 & 51526 & 51348 & $18.5 \%$ \\
\hline All Sectors & 373 & 336 & 394 & $5.6 \%$ & 595417 & 588759 & 612344 & $2.8 \%$ \\
\hline
\end{tabular}

\footnotetext{
${ }^{12}$ This chart is compiled based on data released by HRDC in the 2001 Annual Report (page 39).
} 
Growth and change have characterized the industry since the late 1990s; new businesses have been founded and older companies have merged with former competitors.

Indicative of the acquisition frenzy sweeping the industry, the 2001 Annual Report produced by HRDC highlighted the year 2000 's milestones in communications: ${ }^{13}$ CanWest Global Communications Corp. acquired almost 200 Canadian publications from Hollinger Inc transforming it into "Canada's largest media giant" (HRDC, 2001: 13). That same year, Bell Canada Enterprises (BCE), owner of Canada's largest phone company Bell Canada, purchased Canada's largest broadcaster, CTV which "gave BCE a major content producer to strengthen its Internet presence, Sympatico" (HRDC, 2001: 13). The two traditional sectors within the industry - telecommunications and broadcasting - have continued to coalesce through mergers and consolidation as traditional boundaries between print, broadcasting and the Internet become increasingly porous.

The revised Employment Equity Act has brought about positive change in this industry. Since 1996, because of the amendments, thirteen communications companies have undergone, and twenty-three are currently undergoing, employment equity audits conducted by the CHRC. According to the Act, employers' concomitant obligations are firstly, to remove systemic barriers in the organization and secondly, to institute positive policies and procedures. Mandatory employment equity requirements are based on a set of calibrated performance standards. The audit process has six discrete phases, which emphasize the legislation's consultative undertones. Firstly, the Commission makes initial contact with the company's Chief Executive Officer and conducts preliminary

\footnotetext{
${ }^{13}$ HRDC's Annual Reports are produced using data from the previous year. For example, the 2001 report (released in early 2002) includes statistics and analysis of the year 2000 .
} 
research into the sector and the company's organizational structure. During the subsequent planning phase, the individual designated in charge of employment equity is required to provide the Compliance Review Officer with the organization's employment equity history. The survey phase is critical for determining the extent to which the employer's employment equity activities meet statutory requirements. Strengths and weaknesses are analysed and priorities set for further analysis. The following verification phase includes on-site visits, interviews with employees and union representatives to validate initial findings. The reporting phase involves a report of audit findings submitted to the employer and the negotiation of undertakings, if required. The follow up phase involves the negotiation of the employer's compliance and verification of undertakings if necessary. Clearly the diversity and complexity of modern industry makes the imposition of uniform and inflexible systems of regulation extremely difficult, if not impossible; the back-and-forth nature of the audit underscores the conciliatory nature of this regulation.

Defining a suitable organizational strategy for the problem of employment discrimination must begin with an awareness of the dynamics of organizational change and the nature of specific changes required. Not surprisingly, decision-makers in organizations assign priority to those functions that they believe are most able to contribute to realizing organizations' objectives. The resources applied, the complexity of the systems implemented, and the attention paid to the outcomes flow from this ordering of priorities. As is clear from the case studies of communications companies who have been found in compliance with audits, the audit has made a significant, positive difference because of the resources needed for its implementation. 


\section{Case Studies of the Communications Sector: Social Regulation in Action}

The following case studies were selected because they collectively provide a mix of examples of broadcasting, radio and telecommunications companies in the communications sector representing employees in large and small cites across the country. Three types of sources were consulted: audit reports written by CHRC's Compliance Review Officers, narrative reports produced annually by the selected companies and interviews with employees who managed the audit on behalf of their employer. Together, these three points of view should provide a well-rounded, critical analysis of each audit and its subsequent results. All sources though should be approached with caution. Section 34 of the Employment Equity Act requires information gathered as a result of a compliance audit to be treated as confidential. The Commission though is subject to the disclosure requirements of the Access to Information Act, which supercede the stipulations of the Employment Equity Act. At the time this paper was drafted, thirteen companies had been found in compliance. The CHRC released seven of those audit reports to me while the other six were sent directly from the company after discussion with individual employees regarding my intentions. Audit reports are authored by the regulators, Compliance Review Officers, but frequently involve extensive negotiation with employers and numerous drafts. As they are drafted in tandem with employers, these reports are examples of the increasing "informality and flexibility in the implementation of regulatory mandates," a trend cited by Nemetz, Stanbury and Thompson as characteristic of social regulation (Nemetz, Stanbury and Thompson, 1986:

594). Narrative reports are submitted annually to HRDC and are authored by the regulated, employees usually in Human Resources. The limited value of these reports 
needs to be understood as well; they are public relations documents available to the public online and used by CHRC Officers to determine if audits should be reopened. As such, they are likely written to prove progress has been made and the challenges or regression which may be occurring in workforce populations never surface in these documents. As well, the audit reports and narrative reports are qualitative in nature underscoring the pervasive philosophy underpinning the audit that barrier-free workplace cultures are needed first to move numbers in terms of the representation of designated groups upward over time. A further analysis in two or three years time of the case studies would be required to prove or disprove the qualitative impacts of each audit. Nevertheless, all sources used for these case studies point to the effectiveness of audits as a form of regulating employment equity.

\section{Standard Radio Inc.: "Casual Attention" to Devoted Resources}

Standard Radio Inc. is an example of a company that paid only "casual attention" to employment equity. Prior to the audit, Standard Radio exemplified Patricia McDermott's criticism of the legislation, in that it had been "Most effective in getting employers to collect data about their hiring, retention and promotion of the four designated groups; however, it [was] unclear whether these initiatives [had] been effective in increasing representation" (McDermott, 1993: 96).

A wholly-owned subsidiary of Standard Broadcasting Corporation Limited, Standard Radio Inc. passed its Employment Equity Audit in October 2000 after undertakings were ordered (CHRC: 2000: 1). On the Auditor's first pass, Standard Radio only partially complied with the twelve statutory requirements, making it a concrete 
example of how the three-year Audit initiated positive, measurable change. Similar to many companies in the industry, Standard Radio has high turnover. Due to constant sales and acquisitions of radio stations, one quarter to one third of its workforce turns over each year (Standard Radio, 2000:3).

Academics such as Lum and Williams underscore that there are no clear financial repercussions for not complying with the Employment Equity Act other than a $\$ 50,000$ fine for tardiness, failing to file an Annual Report on time. Still, I would argue that the resources needed to comply with an employment equity audit are significant and that the motivation to complete the audit and mitigate the risk of follow up is very real. Standard Radio Inc. is a case in point. One of the Audit's first outcomes at Standard Radio was that resources were devoted to employment equity. Responding to its poor showing in the first phase, the company committed the full-time resources of an HR Manager and thirty per cent of the Vice President HR to employment equity's time. These resources were dedicated to addressing the Auditor's major conclusions: creating a new survey to verify data, drafting a formal employee systems review and setting hiring and promotion goals. In a rapidly changing industry, a solid understanding of the workforce is imperative. The new survey was critical in that it enabled Standard Radio Inc. to ensure that they knew the composition of its employee population. Data was updated to compare with the 1996 census whereas previously it had only analysed data from the 1991 census.

Further, Standard Radio Inc.'s recruiting of new hires was problematic. In their 1997 submission to HRDC, Standard Radio argued that "There continues to be a lack of talent to draw on for technical jobs. The work pool simply isn't sufficient for positions 
requiring experience, since the experience must come from within the industry" (Standard Radio, 1997: 4). Visible minorities were under represented in major cities. Recruiting tools were inconsistently applied and inaccessible personal networks were the primary intake vehicle. The workforce survey revealed that most recruitment was conducted at the Census Metropolitan Area level - in other words, not nationally but in local communities. The initial Audit showed that Standard Radio Inc. did not understand the reasons for under representation of designated groups in its workforce. To redress the situation, the company set up a committee of employees, trained them to review policies and practices relating to recruitment and selection, career mobility and opportunities, employment conditions and discipline and termination. To measure employee engagement, the Auditor suggested that Standard Radio Inc. analyse its employee survey data by designated group. Accommodation was also an area of improvement. Because of the Audit, a formal Accommodation policy was established, which included procedures for requesting and providing accommodation.

Indicative of the change that was beginning to permeate the business, designated group representation increased in all four groups. Overall representation was at a record high in 2000 (Standard Radio, 2000: 1).

\section{Pelmorex Inc. and NewCap Broadcasting: Enforcement of Management Accountability}

In her report, Abella persuasively argued that "equality demands enforcement. It is not enough to be able to claim equal rights unless those rights are somehow enforceable" (Abella, 1984: 10). Abella was clearly advocating for enforcement at a meta-level: the federal government. Pelmorex Inc. is an example of establishing the 
infrastructure needed to implement employment equity at the grassroots: the managerial level. The employment equity audit gave Pelmorex the tools to do so. Established in 1992, Pelmorex operates in the Telecommunications Broadcasting Industry with 318 employees at their peak period (CHRC, 2001: 6). Pelmorex operates the Englishlanguage The Weather Network and the French-language MéteoMedia across Canada. Over eight million Canadians view its 24-hour specialty networks each week (Pelmorex, 1999: 1).

The audit was initiated in 1999 and closed in 2001. Indicative of the tremendous amount of change in this industry in the late 1990s, at the time it was initiated, CHRC was intending to audit Pelmorex's radio division but the division had just been sold. Instead, the audit's focus moved to the television stations (Morrisette, 2004). The company clearly understood the intense level of work required to comply with the audit. As Vice President of Human Resources, Valerie Morrisette said, "It was rigorous and thorough. Your heart skips a few beats when you're told you are going to be going through an audit" (Morrisette 2004). Pelmorex had just relocated its headquarters from Montreal to Mississauga, Ontario. During this transition period, some employees were agreeing to relocate while others were declining the offer. According to Pelmorex's annual report submitted to HRDC, this change brought about a unique opportunity for employment equity, “...the move not only involves a large number of transfers, but also layoffs and new hires. The extensive recruitment will allow Human Resources to select members of the designated groups without compromise" (Pelmorex, 1997: 1).

Signaling the beginning of the audit, managers were invited to attend employment equity seminars presented by an HRDC Workplace Equity Officer. Management 
accountability was a pervasive theme: materials were distributed by the Officer such as a planning worksheet, which managers were asked to use as a template to outline their short and long term goals (Pelmorex: 2000, 2). After the initial Audit, Pelmorex received good results: they were found in compliance with seven of the twelve undertakings. Some of the change derived from the audit process included greater communication around the workforce survey's availability in alternate formats and how employees could request to change the information in the survey at any time. Pelmorex clearly identified that this change was initiated because of the recently revised legislation "in order to comply with the new Employment Equity Act" (Pelmorex, 1997: 1). While Pelmorex had completed an employee systems review five years prior to the audit, given the scope of organizational changes that had occurred since then, the Compliance Review Officer argued that another review needed to take place.

Frequently, employment practices unwittingly perpetuate past discrimination and operate to freeze the status quo. Designated groups are often screened out not because they lack the essential abilities and skills, but rather because current employment standards reflect the characteristics possessed by those groups who have always filled the positions in the past. The audit process attempts to unearth such instances. Pelmorex's extensive review included a comprehensive survey of employees and managers on policies and practices related to the nine employment systems namely recruitment, selection, hiring, development, training, promotion, retention, termination and accommodation. The survey revealed unsuccessful outreach measures and overstated qualifications on many entry-level job descriptions. Analysis revealed that managers were inconsistently evaluating, recruiting and managing employees. Action required 
included management training and a review of job requirements. As part of the audit, job descriptions were redrafted to outline the "minimum" rather than the "ideal" qualifications to attract the widest possible pool of candidates (Morrisette 2004). Internal research also revealed that there was no tracking system in place to determine if resumes were being received from designated group members. Examples of corrective measures included in Pelmorex's subsequent Employment Equity Plan are: ensuring job postings are received by associations representing designated groups and tracking results. As a result of the Audit, Pelmorex is increasingly reaching out to diverse candidates: In 1997, job postings were only sent to two associations focusing on the employment of designated groups. In 2001, Pelmorex staff was establishing strategic relationships with aboriginal and special need student associations. As well, communication around accommodation has occurred via paycheque inserts. Automatic doors to office buildings will be installed as well as in the broadcast centre, ensuring employees with disabilities are able to enter and participate in the studio (Pelmorex, 2000:4).

As part of the employment systems review, a Diversity Committee reviewed all of Pelmorex's internal Human Resources policies to identify systemic barriers. In analyzing the Special Leave Day policy, the Committee realized that employees who were using these two days for religious holidays, would not have access to any other days for personal emergencies. To solve this problem, the policy was redrafted into two parts: one for religious holidays and another for personal emergencies (Morrisette 2004). The Employment systems review has resulted in significant the implementation of systemic remedies to combat systemic discrimination. 
Similar to Standard Radio, significant company resources were dedicated to employment equity. As Vice President of Human Resources at Pelmorex, Valerie Morrisette says "There is a lot you need to do - it's rigourous" (Morrisette 2004). "We had one person assigned to this for one entire year" (Morrisette 2004).

In the same way that the employment systems review provided Pelmorex with a tool to focus its efforts, the workforce analysis also provided Pelmorex with a better understanding of workplace barriers. Says Morrisette, "The workforce analysis is an amazing tool. [It] helped us focus on our gaps. We knew exactly where we were exceeding market availability and where we were not. ... When we were recruiting or outreaching to build a database of qualified candidates, we knew where to focus" (Morrisette 2004).

Pelmorex has for four years enforced corporate accountability by initiating criteria in management bonuses for filling gaps in workforce representation. "[Employment equity has just trickled down throughout the entire company. It's just part of our culture right now. Everybody's living it. It's not just the HR team" (Morrisette 2004). For the past two years, an annual employee survey asks if the company is committed to employment equity. The results for this question are the highest out of all the survey questions at $94 \%$ of employees in agreement (Morrisette 2004). Clearly, management accountability for an equitable workplace is well understood by the employee population.

While the numbers of internal changes are clear, Pelmorex is now actively engaging the public. Realizing its unique ability to advocate for employment equity through broadcasting, two external Diversity Advisory Committees are being established. 
Participants in the committees will be the Canadian National Institute for the Blind, the Canadian Hearing Society and Indian and Northern Affairs.

Pelmorex received "C" ratings for representation in all four designated groups in 1992 indicating that all groups were very poorly represented (Canada, 1991: 47). Ten years later, the results had significantly improved: In 2002 year, they received straight "A"s (Canada, 2003: 41). As Morrisette says when reflecting on the change within Pelmorex, "Legislation works" (Morrisette, 2004). There is a clear indication that Pelmorex's success in implementing employment equity is because they understand its competitive advantage: "As the war for talent increases, we know that talent is fast becoming a scarce resource. As such, we look for the best talent - wherever we can find it. We understand the business case for diversity" (Morrisette, 2004).

Like Standard Radio, NewCap Broadcasting is another telling example of the Employment Equity Audit's impact on changing a workforce culture. With 334 employees, NewCap operates radio stations in Alberta, Ontario, New Brunswick, Nova Scotia, Prince Edward Island and Newfoundland. The composition of NewCap's employee population has dramatically expanded; since it filed its first Employment Equity Report with HRDC in 1990, NewCap has grown 66\% (NewCap Broadcasting, 2000: 1).

As NewCap's employee population rose, more and more employees needed to complete a self-identification survey to determine if they were a designated group member. A key finding from the initial audit was that the identification of employees was not kept confidential. Employees's completed workforce survey was stored in their 
personnel file, compromising the confidentiality of the information. Going forward, this information will now be kept separate.

An employee systems review was also an undertaking for NewCap, which uncovered key barriers. Specifically, the reliance on word-of-mouth referrals and informal methods of selection were identified as barriers to employment. The hiring of on-air announcers was identified problematic. Typically, selection includes the assessment of a CD or audio file of the candidate's voice for such qualities as sound of voice, good communication skills, sense of humour and how the candidate would relate to a target market. The Auditor identified systemic biases in this process. Specifically, the ingrained practice of using non-ethnic names and selecting voices that were linguistically 'mainstream' would lead to the perception of Aboriginal and visible minority listeners that this industry was exclusive and their opportunities limited. To redress these issues, NewCap now requires all managers to establish and maintain outreach and recruitment lists for respective locations and to document all outreach efforts. As well, NewCap is developing promotional materials aimed at attracting more people from the designated groups to the radio industry.

Perhaps the most groundbreaking outcome of the employment equity audit is that NewCap has developed a program to include employment equity as a factor in managers' compensation packages similar to Pelmorex. Both companies have been forced to rethink the concept of accountability for employment equity because of the audit process. Internal workplace policies have been significantly reworked to eliminate potential discrimination. While this is an important step, a further analysis will be required in the 
next two or three years to determine if the representation of designated group members has moved accordingly.

\section{Canadian Satellite Communications Inc. (Cancom) and Star Choice Communications Inc.: Management Turnover}

Since management accountability for employment equity is so critical, communications companies are often challenged by frequent turnover in managerial teams. Another example of the rapid pace of change in the industry, Canadian Satellite Communications (Cancom) Inc.'s entire management team was replaced in 1999. Cancom implements and manages satellite-based communications systems. The assets of Cancomn's parent company, WIC Westem International Communications Ltd. were divided between Shaw Communications and CanWest Global. Cancom went to Shaw Communications (CHRC, 2000:17).

Initiated prior to the acquisition, the audit came at a time when the Cancom Employment Equity Committee was defunct and minimal progress had been made towards an equitable, supportive workplace. In April of 1998, three key senior executives resigned from the company at the same time Cancom announced the acquisition of Starchoice, a direct-to-home satellite video provider with 350 employees. Two years later, CHRC found Cancom to be in compliance with the Employment Equity Act (CHRC, 2000: 1).

Cancom had a lot of progress to make. In 1991, there were no Aborginal people or people with disabilities in its workforce. Women were poorly represented although slowly trending upwards. Visible minorities were represented in its workforce but primarily in lower level jobs (EIC, 1991: 46) 
In the employment systems review, specific gaps were identified in the areas of "Women in Middle and Other Mangagers; Skilled Sales," "Persons with Disabilities in Mddle and Other Managers, Skilled Sales, Clerical," "Visible Minorities in Middle and Other Managers, Skilled Sales, Clerical." Word of mouth recruitment was perpetuating the existing profile of Cancom's workforce. In his report, the Compliance Review Officer drew specific attention to the low representation of people with disabilities in Cancom's workforce (CHRC, 2000: 15).

One of the measures Cancom implemented as a result of the Act was a significant review of its accommodation policy. While originally drafted to focus only on people with disabilities, Cancom revised it to include all designated groups. In addition, the selfidentification aspect of the employee survey was redrafted so that employees could identify themselves as a member of more than one designated group.

Unfortunately, while representation at Cancom had been improving, the addition of Star Choice resulted in a decline in overall representation for all designated groups with the exception of people with disabilities from 1999 to 2000 . From 2000 to 2001, there were again declines in three of the four groups. Still, Cancom has shown improvement in workforce representation. In the 2001 HRDC report Cancom received "A" ratings for women, Aboriginal people (who were nonexistent in its workforce ten years earlier) and visible minorities indicating good representation and a favourable comparison with other employees in terms of hires, promotions and salaries. Representation for people with disabilities was poor - although progress had been made since the time when there were zero in 1991 (HRDC, 2001: 35). 
While Cancom is now able to utilize the resources of Star Choice's HR department, time will tell if another audit will be initiated as Cancom commitment to employment equity may be diluted due to the acquisition. The Audit process though did instigate significant, positive change at Cancom because it prescribed a comprehensive, problem-solving and planning process by which Cancom could eliminate systemic discrimination using a process which utilized corporate and institutional planning techniques.

\section{Telus: An Effective Audit Despite an Environment of Mergers and Acquisition}

Telus Corporation presents yet another illustration of the degree of change occurring in the communications industry, Telus Communications Inc. merged with BC Tel in February of 1999. Prior to the merger, audits had been initiated at both companies. Since the company's population now looked completely different, CHRC only found Telus in compliance with one of the twelve undertakings shortly after the merger. Two other major purchases were made not long afterwards: Quebec Tel, a full-service telecommunications provider and Clearnet Communications, Inc., a national digital wireless company (CHRC, 2002: 1). Almost three years later, they were found in compliance. The long audit was likely a result of the change and complexity in the industry at the time, which was embodied in Telus Corporation. Elaine McKinlay, Director, Privacy and Employment Equity at Telus attested to the flexibility inherent in the audit process, the decision to move forward on the audit was made by both parties: "We finally kicked off in 2000 when both the company and the CHRC felt it was time to move forward aggressively" (McKinlay, 2004). The results of the initial audit revealed that Telus had a long way to go: they were found out of compliance with eleven of the 
twelve undertakings. Says McKinlay, "There were some pieces of it we were doing but a lot of it had fallen by the wayside through the merger and subsequent changes" (McKinlay 2004).

Two gaps clearly identified and addressed in the audit included the representation of visible minorities and women in the "Other Sales \& Service" category, which at Telus included primarily jobs as caretakers and janitors. The Employment systems review described by McKinlay as "the meat and potatoes" of the audit revealed an "image issue with regard to the number of women who seek out these types of jobs" (McKinlay 2004) (CHRC, 2002: 11). In addition, the reliance on recruiting software, RecruitSoft, to sift through unsolicited resumes received online and from job search web sites and determine a short list of qualified candidates, was determined to have an adverse impact on designated group members. To mitigate this risk, Telus has asked its software provider to provide a breakdown of applicants by designated group. As well, potential employees were often pre-screened on the telephone prior to face-to-face interviews and the Audit revealed that people with disabilities were not offered an alternative format for this interview.

In the early 1990s, Poole and Rebick proposed that a dangerous blindspot in the original Employment Equity Act was that it concerned itself with numbers and not a workplace culture. I would argue that the revised Act does fill in this gap. In addition to problems identified with the recruitment process, the Audit also revealed that the employee experience was not analysed according to designated groups. Telus' annual "Pulsecheck" survey of its work environment is now being redrafted to include an analysis of designated group and occupational group. This new data collection will 
enable Telus to determine if for instance, women in the "Other Sales \& Service" category have a different employee experience than women in other occupational groups and actions will be set accordingly to remedy potential discrimination.

A clear barrier uncovered by the Audit was the lack of a comprehensive Accommodation policy. The policy was rewritten and a comprehensive communication strategy was developed for the launch of the policy. As well, like many other companies, the Audit required Telus to redraft their workforce survey, expanding the definition of people with disabilities and informing employees they could self-identify in more than one group (McKinlay 2004).

Similar to the other examples, significant corporate resources were needed to successfully complete the audit. Telus had a director on this full-time, a team of systems staff, labour relations people, an external consultant and HR consultants who understood the jobs in this business. This large amount of resources and expertise were dedicated to the audit because as McKinlay argues, "no company ...want[s] to be found out of compliance" (McKinlay 2004). Over the long term, McKinlay suggests that the systems are in place to keep employment equity front and centre at Telus: "We made some really good inroads. We now have ongoing processes to keep employment equity current" (McKinlay 2004).

While Telus was finally found in compliance with employment equity, in 2002 it announced that it would be downsizing significantly (CHRC, 2002:1). If the Audit has been effective, vulnerabilities such as the poor representation of visible minorities and inconsistent accommodation will not be magnified by impending layoffs. Frequently, employees who were last hired are the first employees to be terminated from the 
organization in restructuring environments. As Telus is heavily unionized, this trend is extremely likely and as such, the corporation will need to mitigate this potential risk as they collapse and streamline the organization. Time will tell if the proportional representation of designated groups shrinks at the same or a higher rate as the overall employee population.

\section{Rogers Broadcasting Limited: Growth and Contraction}

Indicative of the industry, Rogers Broadcasting Limited has grown tremendously in the last few years. In 1999, they acquired ten new stations. With 1573 employees in 2001, Rogers Broadcasting operates as three divisions: Radio (a total of 30 stations across Canada), Television (OMNI, a cross-cultural station) and The Shopping Network (televised home shopping) (Rogers, 1999: 1).

To disseminate its commitment to diversity, Rogers Broadcasting has produced a brochure and video distributed to all employees and new hires. Likely as part of an Employment Equity Audit, Rogers Broadcasting completed a full Employee Systems Review in 1999 as well as an internal pay equity audit.

In radio operations, a key position is that of "Radio Program Director". To ensure that half of the successful candidates are at least from one of the four designated groups, Rogers Broadcasting established a "Program Director Understudy Program" in 1996, which includes training, mentoring and job shadowing. A similar program is being run in the Sales Management function of the radio division (Rogers, 1999:4).

The workforce analysis resulted in a workforce accessibility audit conducted in 2000. As with many companies in this industry, the hiring and advancement of people with disabilities is problematic. A workforce analysis in 1999 revealed the areas where 
Rogers Broadcasting Limited still needs to make progress. While on a national scale, Rogers' workforce analysis (an audit component) indicates that they are primarily representative of the availability data for the designated groups, there are two areas of concern: on a national basis, the representation for people with disabilities remains poor and, gaps exist for visible minorities in Toronto in some occupational groups. Hiring goals and timetables were established in 2000 . Some of the initiatives, which have come to fruition since the audit include an adaptive technology lab which undertakes functionality testing of information technology applications being introduced into the workplace (Rogers, 2001: 4).

In early April 2000, Rogers Broadcasting Limited announced the sale of its crosscultural station OMNI also known as "Toronto One" which could easily have been viewed as an example of the broadcasting sector functioning as advocates of employment equity through innovative programming promoting diversity in Toronto. While further analysis would be required, it is likely that this sale will severely impact representation at Rogers Broadcasting specifically in the area of visible minorities. As with all of the case studies, time will be needed to accurately measure their success and determine if the early indications of positive change will continue or be curtailed as the industry expands and contracts.

\section{The Corporate Costs of Social Regulation}

Heterodox to Lum and Williams' assertion that there are no significant financial repercussions for companies who fail to comply with the Act, these case studies clearly exemplify that implementing employment equity does involve noteworthy costs (Lum 2000). The learning curve required by companies is frequently cited as a major 
challenge: Said one employer, "On a personal note, I was new to employment equity and it was certainly a good way to learn what it's all about" (McKinlay, 2004). "[The Audit is] very helpful in terms of informing organizations of what their responsibilities are and how it works. The flipside is you have to become and expert in it because there are so many ifs ands or buts" (McKinlay, 2004). Extensive resources are required to undertake a thorough analysis, to change, adapt, and create more equitable employment systems, and to implement specific measures to remedy the effects of past discrimination. Secondary costs include the possible diversion or expansion of management commitment away from immediate objectives and the potential for disruption in the business process no matter how thorough the preparation. In all cases, these resources were devoted to the audit to mitigate and avoid future costs: the potential threat of another audit and the resources that it would unquestionably entail.

HRDC uses its Annual Reports to give employers 'ratings'. An " $\mathrm{A}$ " rating "indicates superior performance in all indicator" (HRDC, 2001: 24). An "A" rating is defined as "The organization made outstanding progress in improving the representation of the group in its workforce through hiring and promoting group members. The situation of the designated group in the company compares very well with the group's labour market availability, received adequate shares of hirings and promotions, compares favourably with other employees in terms of salary and occupational distribution and does not adversely suffer from termination compared to other employees" (HRDC, 2001: 24).

When comparing the number of $\mathrm{A}$ ratings in communications to the second largest industry, banking, it is clear that banking has received better reviews (See Figure 
2). As exemplified by the chart below, banking has progressed further in terms of eliminating workplace discrimination for the two largest designated groups, women and visible minorities. Perhaps the significant amount of change and turnover in people has adversely impacted the communications industry's ability to score better. Still, communications has received more A ratings than banking for Aboriginal peoples an anomaly which needs to be better understood.

Figure 2: Industry Comparison: Banking and Communications ${ }^{14}$

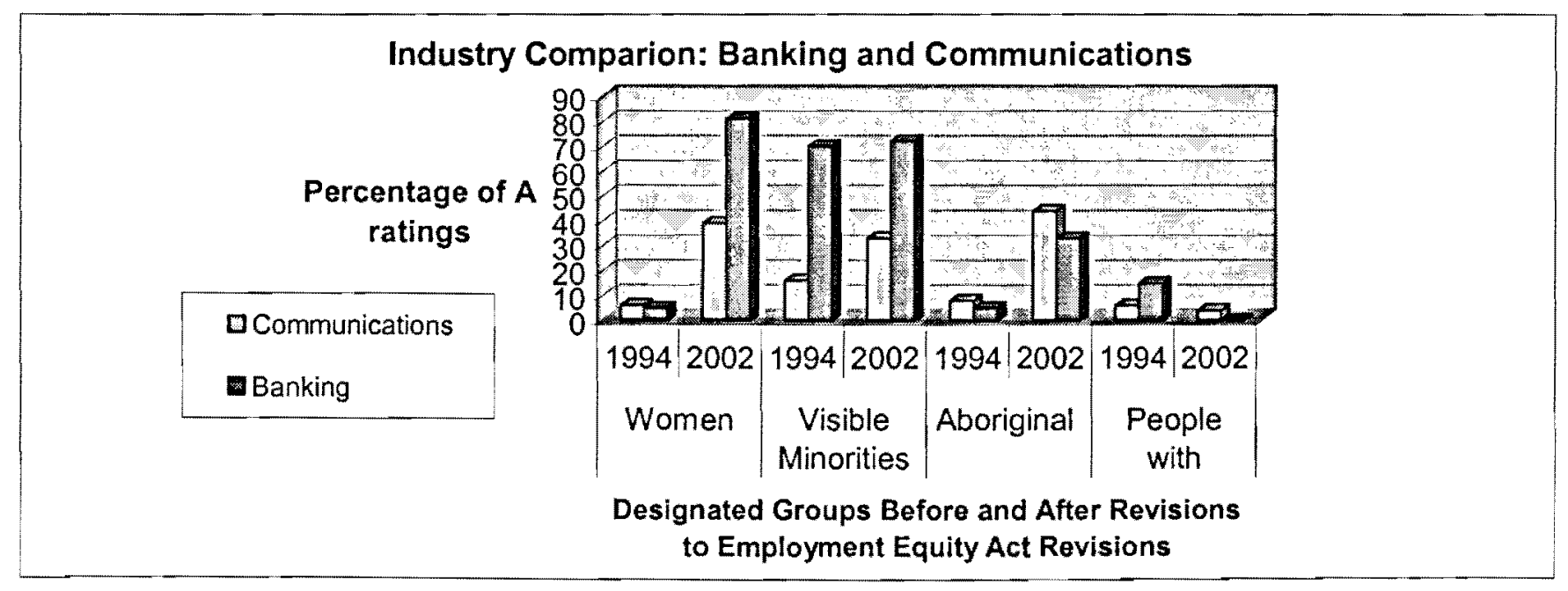

The Public Sector Costs of Social Regulation

While it is critical to understand the broad scope of the Act, it is equally important to recognize its boundaries. Explicitly stated in the legislation is that employers are not required to implement initiatives that would constitute undue hardship, to invent new positions, establish quotas or hire and promote unqualified candidates. As well, the legislation argues that "wherever possible, cases of noncompliance will be resolved through persuasion and the negotiation of written undertakings and that directions be

\footnotetext{
14 This chart is compiled based on data released by HRDC in the 1995 Annual Report (pages 35-44) and 2003 Annual Report (pages 38-51).
} 
issued and that applications for orders only be made as a last resort" (Statutes of Canada, 1996: Chapter 44). The flexibility inherent in the legislation is in line with a philosophy that employment equity requires the cooperation and buy-in of employers and that diminutive steps will inevitably lead to seismic change in due course.

Such "negotiation" and "persuasive" requires numerous resources not only on the part of corporations, but also from the CHRC. A simultaneous strength and weakness of the Act's audit process is the human resources required to execute it. Each auditor works with several organizations simultaneously. The Audit process is lengthy: according to the $\mathrm{CHRC}$, on average, up to three years are needed before the Commission issues a final compliance report to an employer who required undertakings (CHRC, 2001: 4). The process is lengthened in part by few Compliance Officers. Frequently, auditors juggle several corporate audits simultaneously. Given the breadth of change in the communications industry, it appears that some of the audits in this industry may take even longer. Characteristic of the neo-liberal age, the personnel needed for regulation is often constrained. The audit process may be challenged as the public sector shrinks: according to Phillips, this area of CHRC decreased from 29 to 21 Compliance Review Officers in 2003 or about twenty-eight percent of its net full-time employees (Phillips, 2003). Perhaps because of thin resources, companies felt the CHRC did not always move at the same speed as business: "The bureaucracy slowed the process down. Much of the correspondence is done via paper. Sometimes [CHRC] would ask for something and you'd wait three months to see if you were in compliance or not" (McKinlay 2004). As the public sector diminishes, the ability to give the Employment Equity Act "teeth" will simultaneously be hindered. 
This impact will be felt because the Compliance Review Officer plays such an intrinsic role in implementing the Act's "teeth." As one HR professional said, "I believe the Compliance Officer will be making all the difference in the Employment Equity Act" (Morrisette, 2004). Maintaining good relationships with the auditor is considered essential to an effective audit: "We had a very good rapport with our Compliance [Review] Officer. It was a mutual, good, positive experience" (Morrisette, 2004). These Officers need to be well-equipped to evaluate and measure corporate success. While the Act covers a cross-section of heterogeneous industries (banking, transportation and communications), Compliance Review Officers currently do not specialize in specific sectors. Phillips argues that general expertise allows for "better analysis" (Phillips 2003). Compliance Review Officers are instead provided with industries studies compiled by external consultants and are required to analyse the performance of individual companies. One of the criticisms of the CHRC is its inability to translate the legislation into clear business objectives. To remedy this situation, one employer hired an external consultant "to make it practical" and interpret the legislation "into business terms" (McKinlay 2004). One way of doing this would be to provide companies with positive reinforcement. As one company representative suggested, "If a company is doing really well, acknowledge it" (Morrisette 2004).

Corporations have also recommended that the CHRC focus on increasing its own profile. For instance, a suggestion was made to leverage the CHRC "If you are looking at the business community and government to be partners, they need to capitalize more on taking advantage of those opportunities" (McKinlay 2004). 
Since the Act received Royal Assent in 1995 and came into force in 1996, a legislative review was required commencing in 2001 . The CHRC made several recommendations to the Act but overall, argued it was too early to advocate for deepseated change. They maintained that in order to answer the fundamental question of whether or not the present Act achieved its goal of reducing the under representation of designated groups, they needed to first monitor employers who were in compliance. Still, the CHRC did identify areas of improvement. These recommendations mostly relate to clarifying terms in the Employment Equity Act itself. For instance, CHRC advocated for the clarification of "the objective of the employment systems review and its relationship to both the workforce analysis and the employment equity plan" (CHRC, 2001: 2). One of the outcomes of this review is implementing community engagement into the CHRC process. Specifically, CHRC recommended erecting a process that would ensure that community groups are able to provide input into the Commission's implementation of its responsibilities under the Act (CHRC, 2001: 4). The CHRC is conducting an independent evaluation of its effectiveness through a survey of employers, private sector consultants (Phillips, 2003). Those results may uncover some of the issues around resourcing and business expertise.

When viewed as a strategic investment, both in terms of improvement in overall labour productivity and the avoidance of costly human rights litigation or future public controversy, the overall return should be seen as positive. Still, in light of economic downturns, the audit component of the Employment Equity Act augments the need to eliminate systemic barriers on fluctuating priority lists. In general, there is a presumption that many legislative policy initiatives are facilitated, and indeed may even be made 
unnecessary, by an expansive economy. In a growing economy discrimination itself may dissipate as employers seek new sources of labour supply and as they reevaluate their conventional hiring policies. Predictions about the future though are mixed: As the workforce ages, the potential impeding labour shortage may office openings to designated groups. However, as Mike Burke and John Shields have argued, labour market trends over the last number of decades have indicated a growing amount of "job poor growth" concentrated in contingent work. That is, standard full-time employment is no longer the norm (Burke and Shields, 2000: 98-23). Given that communications companies are expanding and contracting so quickly, employment equity needs to remain a priority. The audit does help to keep issues of workplace discrimination at the forefront. As one employer argued, "The business world right now after challenges in the stock market is really a dog eat dog world. If you don't have a lever to keep this front and centre, it will fall to the back" (McKinlay, 2004).

\section{Conclusion: The Employment Equity Act, A Case of Regulation that Works}

For many years prior to the Employment Equity Act, voluntary affirmative action existed in several manifestations in the public service with varied results. ${ }^{15}$ The private sector though remained largely untouched by the concept. In the early $1980 \mathrm{~s}$ communications industry, employment equity was non-existent.

\footnotetext{
${ }^{15}$ Prior to the original Employment Equity Act, the federal government's experience with similar programs was tenuous. After World War II, the Public Service Employment Act gave returning veterans preferential treatment in relation to job opportunities. The program was successful but worked to the detriment of women - many of whom were jettisoned from the Canadian labour force once the troops retunred (Abella, 1985: 107). Beginning in the 1980s, voluntary affirmative action programs existed as pilot projects within the public service sector. While the Treasury Board Secretariat and the Public Service Commission were mandated to review action plans, according to the Report of the Parliamentary Committee on Equality Rights, "many federal departments and agencies [had] still not implemented special employment equity programs" (Abella, 1985: 107).
} 
This began to change when the original Employment Equity Act came into effect in the Mulroney era and this social regulation became legitimised. Its impact though was mitigated by a period characterised by shrinking federal bureaucracy while increasing the number of jobs in the private sector. Michael Moran has argued that avoiding a "cumbersome, onerous bureaucracy" was a key political objective in Britain during this period (Moran, 2001: 32). Market centred solutions were the mainstay of this political era overseas in Canada as well as exemplified by the first Employment Equity Act, which allowed corporations to self-regulate.

In her research on the opportunities and roles for Canadian women, Janine Brodie identifies a seismic shift as "competitiveness," "restructuring" and "globalization" have manifested themselves into the Canadian lexicon. For Brodie, the neoliberal consesus' main themes can be summarized as: maximize exports, trim social spending, curtail state economic regulations and enable market forces to restructure national economies as parts of transnational or regional trading blocks (Brodie, 1993: 4). Brodie persuasively argues that public policy is always a reflection of the current government's agenda. The Macdonald Commission for example, was appointed in 1982 by the Liberal federal government to determine how to reverse the worst economic downturn Canada had faced since the 1930s. Abella's report was a product of the same era characterized by stagflation - a simultaneous increase in both inflation and joblessness - which resulted in the Liberal government's defeat (Brodie, 1996: 17). At that moment, the early 1980s, there was no political mileage in being out of step with corporate Canada. Brodie suggests that with regards to the Mulroney era, historians have judged the regime to be one of the most radical and explicitly ideological in Canadian history. 
During Mulroney's second term, the 1991 "Redway Report" reviewed the Employment Equity Act to determine its success rate. How the Act had initiated change in the communications sector was clear: little progress had been made. Submissions from organizations such as the National Action Council revealed that the Act had resulted in minimal impact on the upward mobility for women in the workforce, specifically citing a case study of the CBC. The Toronto Women in Film and Television argued in the 1991 review that unions were inflexible in implementing employment equity (Timpson, 2001: 159). The submissions reflected a rising awareness of work cultures and their ability to maintain or repudiate equitable practices (Timpson, 2001: 159),

Academics John Shields and Stephen McBride argue that the shift towards a neoliberal agenda in which policies are increasingly shaped by corporate interest became even more profound with the election of the Liberal government in 1993. While this market-centred approach may have characterized many policies in this era, I would suggest that the revisions to the Employment Equity Act were an exception to the rule as they instituted more - not less - government intervention. Subsequent Prime Minister Jean Chretien's "Red Book" posited that human resources would be integral to Canada's economic future (Timpson, 2001: 173). It promised to reinforce the Employment Equity Act in two significant ways: increase its scope to include the federal public service and strengthen the Canadian Human Rights Commission (CHRC)'s ability and authority to monitor compliance with the Act (Timpson, 2001: 173). The Liberal government, elected primarily by seats in the province of Ontario needed to carefully mitigate the backlash against employment equity in Ontario with a commitment to equality in 
employment. As such, the revisions were carefully positioned in the press release as beneficial to the broad Canadian workforce:

'This new Act is not only advantageous to designated groups. A fair and barrier-free workplace means a better working environment for all employees. Utilizing the full potential of our diverse workforce is essential to Canada's future success,' said Minister Gagliano (HRDC, 1996: 1).

The Chretien model of employment equity was packaged using a neo-liberal argument: only by moving to make the fullest use of available qualified workers would the Canadian economy be able to marshal the forces needed for growth and make the labour market adjustments required to prolong that upward momentum. In other words, for the Chretian government, economic growth depended on bringing into the labour force those groups who had been excluded from it and therefore permitting the fullest use of Canadian skills and abilities. In an era of deregulation, the revised Employment Equity Act represented an anomaly as it legislated increasing government involvement through CHRC's Audits. As the case studies have demonstrated, these Audits have broken down barriers in the workplace for the four designated groups, proving that regulation is necessary and effective to achieve employment equity.

It is clear from these case studies that inserting the audit component to the Employment Equity Act explicitly fortified the 1986 legislation. Curiously, many of the recommendations put forth in the initial Abella report advocated for a compliance component. Had the audit process been initiated in 1986 instead of ten years later, large employers such as Canadian communications companies would be ten years ahead in their analysis of workplace discrimination. As Lum and Williams explicitly argue, the major problem with the revised Employment Equity Act is that it governs only eight percent of the workforce, meaning that it has marginal implications for employment 
opportunities available to the majority of the Canadian population. 


\section{Bibliography}

Abella, Rosalie. "Equality in Employment: A Royal Commission Report." Canadian Women Studies/Les chaiers de la femme. 6:4 (1985): 6.

Bird, Florence. Royal Commission on the Status of Women in Canada. Ottawa: September 28, 1970.

Armstrong, Pat. "The State and Pay Equity: Juggling Similarity and Difference, Meaning, and Structures." In Eds. Patricia Evans and Gerda R. Wekerle. Women and the Canadian Welfare State: Challenges and Change. Toronto: University of Toronto Press. 1997.

Brodie, Janine. "A Canadian Women, Changing State Forms and Public Policy." Women and Canadian Public Policy. Toronto: Harcourt, Brace. 1993. 1-28.

Brodie, Janine. Politics on the Margins: Restructuring and the Canadian Women's Movement. Toronto: Fernwood. 1996.

Burke, Mike and John Shields. "Tracking Inequality in the New Canadian Labour Market.” In Eds. M. Burke, C. Mooers and J. Shields. Restructuring and Resistance: Canadian Public Policy in an Age of Global Capitalism. Halifax: Fernwood. 2000. 98-123.

Employment and Immigration Canada. Annual Report: Employment Equity Act: 1991. Ottawa: Employment and Immigration Canada. 1992.

The Employment Equity Act review: a report to the Standing Committee on Human Resources Development and the Status of Persons with Disabilities. Hull, Quebec: Human Resources Development Canada. 2001.

Fudge, Judy. "Fragmentation and Feminization: The Challenge of Equity for LabourRelations Policy." In Ed. Janine Brodie. Women and Canadian Public Policy. Toronto: Harcourt, Brace. 1993. 57-86.

Geller, Carole. "A Critique of the Abella Report." Canadian Women Studies/Les chaiers de la femme. 6:4 (1985): 20-22.

Human Resources Development Canada. News Release, 30 May 1996. Ottawa: Human Resources Development Canada. 1-2.

Human Resources Development Canada. Annual Report: Employment Equity Act: 2001. Ottawa: Human Resources Development Canada. 2002.

Human Resources Development Canada. Annual Report: Employment Equity Act: 2002. Ottawa: Human Resources Development Canada. 2003. 
Loney, Martin. The Pursuit of Division: Race, gender and Preferential Hiring in Canada. Montreal: McGill-Queen's University Press. 1998.

Lum, Janet M. and A. Paul Williams. "Out of Sync with a 'Shrinking State'? Making Sense of the Employment Equity Act (1995)." In Ed. Mike Burke, Colin Mooers and John Shields. Restructuring and Resistance: Canadian Public Policy in an Age of Global Capitalism. Halifax: Fernwood Publishing. 2000. 194-211.

Marsden, Lorna R. "The Importance of Studying Affirmative Action," Canadian Women Studies/Les chaiers de la femme. 6:4 (1985): 12.

McBride, Stephen and John Shields. Dismantling a Nation: The Transition to Corporate Rule in Canada. Halifax: Fernwood Publishing, 1997.

McDermott, Patricia. "Pay and Employment Equity: Why Separate Policies?" In Ed. Janine Brodie. Women and Canadian Public Policy. Toronto: Harcourt, Brace. 1993. 57-86.

Montgomery, Charlotte. "Tories Consider Buying Policy as lever for Job Equality Laws." Globe and Mail. 22 November 1988. A5.

Moran, Michael. "The Rise of the Regulatory State in Britain." Parliamentary Affairs. No. 54 (2001): 19-34.

Nemetz, Peter N., W.T. Stanbury and Fred Thompson. "Social Regulation in Canada: An Overview and Comparison with the American Model." Policy Studies Journal. Volume 14, No. 4 (1986): 580-603.

Poole, Phoebe-Jane. 1994. "Not Another Hundred Years: The Failure of the Federal Employment Equity Act." Canadian Labour Law Journal 1, 4 (Spring). 341367.

Prentice, Alison, Paula Bourne, Gail Couthbert Brandt, Beth Light, Wendy Mitchinson and Naomi Black. Canadian Women: A History. $2^{\text {nd }}$ ed. Toronto: Harcourt Brace Canada. 1996.

Reed, Carole Ann. "Contradictions and Assumptions: A Report on Employment Equity in Canada." Resources for Feminist Research. Fall 1995 - Winter 1996. 46-48.

Saloojee, Anver. "Containing Resistance: The Neoliberal Boundaries of Employment Equity." In Ed. Mike Burke, Colin Mooers and John Shields. Restructuring and Resistance: Canadian Public Policy in an Age of Global Capitalism. Halifax: Fernwood. 2000. 287-305. 
Statutes of Canada. An Act Respecting Employment Equity: The Employment Equity Act. Ottawa: Queen's Printer for Canada. 1996. Chapter 44.

Silberman Abella, Rosalie. Report of the Commission on Equality in Employment. Ottawa: Canadian Government Publishing Centre. 1984.

Timpson, Annis May. Driven Apart. Women's Employment Equality and Child Care in Canadian Public Policy. Vancouver: UBC Press. 2001.

Wilson, Sue. "Paid Work, Jobs and the Illusion of Economic Security." In Ed. N. Mandell. Feminist Issues: Race, Class and Sexuality. $4^{\text {th }}$ edition, Toronto: Pearson Education. Forthcoming.

\section{Audit Reports}

Canadian Human Rights Commission. Employment Equity Compliance Review: Bell Mobility. November, 27, 2000. 1-22.

Canadian Human Rights Commission. Employment Equity Compliance Review: Canadian Satellite Communications Inc. Compliance Report. April 20, 2000. 118.

Canadian Human Rights Commission. Employment Equity Compliance Review: NewCap Broadcasting: a division of Newfoundland Capital Corporation Compliance Report. January 22, 2003. 1-28.

Canadian Human Rights Commission. Employment Equity Compliance Review: Pelmorex Inc./The Weather Network Compliance Report. January 15, 2001. 127.

Canadian Human Rights Commission. Employment Equity Compliance Review: Standard Radio Inc. Compliance Report. October 3, 2000. 1-22.

Canadian Human Rights Commission. Employment Equity Compliance Review: QuebecTelephone. November, 20, 2000. 1-30.

Canadian Human Rights Commission. Employment Equity Compliance Review: Sprint Canada Ltd. May 19, 2000. 1-25.

Canadian Human Rights Commission. Employment Equity Compliance Review: Telus Corporation Compliance Report. July 26, 2002, 1-33.

Canadian Human Rights Commission. Employment Equity Compliance Review: Videon CableSystems Inc. November, 27, 2000. 1-15.

Canadian Human Rights Commission. Employment Equity Report. Ottawa: Minister of Public Works and Government Services Canada. 2001. 


\section{Narrative Reports}

Canadian Broadcasting Corporation (CBC). "2000 Employment Equity Report." May 2001. 1-8.

Canadian Satellite Communications Inc. (Cancom) \& Star Choice Communications. “1997 Employment Equity Report.” May 1998. 1-8.

Canadian Satellite Communications Inc. (Cancom) \& Star Choice Communications. "2000 Employment Equity Report." May 2001. 1-5.

Canadian Satellite Communications Inc. (Cancom) \& Star Choice Communications. "2001 Employment Equity Report." May 2002. 1-8.

NewCap Broadcasting. "1997 Employment Equity Report.” May 1998. 1-3.

NewCap Broadcasting. “1999 Employment Equity Report.” May 2000. 1-2.

NewCap Broadcasting. “2001 Employment Equity Report.” May 2002. 1-3.

Pelmorex Inc. "1997 Employment Equity Report.” May 1998. 1-7.

Pelmorex Inc. "1999 Employment Equity Report." May 2000. 1-7.

Rogers Broadcasting Limited. "1997 Employment Equity Report." May 1998. 1-7.

Rogers Broadcasting Limited. "1998 Employment Equity Report." May 1999. 1-7.

Rogers Broadcasting Limited. "2000 Employment Equity Report." May 2001. 1-6.

Standard Radio Inc. “1997 Employment Equity Report." May 1998. 1-6.

Standard Radio Inc. "1999 Employment Equity Report." May 2000. 1-5.

Standard Radio Inc. "2000 Employment Equity Report." May 2001. 1-7.

\section{Interviews}

McKinlay, Elaine. Director, Privacy and Employment Equity, Telus. April 5, 2004.

Morrisette, Valerie. Vice President, Human Resources, Pelmorex. March 30, 2004.

Phillips, Rhys. Chief of Legislation and Program Development in the Employment

Equity Branch, CHRC. October 15, 2003.

Smith, Valerie. Manager, Human Resources, Standard Radio. April 2, 2004. 


\section{Appendix A: Letter to CHRC to Access Audit Reports}

Audrey Wubbenhorst

6266 Starfield Cres.

Mississauga, ON

L5N 1 X4

Ms. Deborah Cansick

Access to Information and Privacy

CHRC

344 Slater, $8^{\text {th }}$ Floor

Ottawa, ON

$\mathrm{K} 1 \mathrm{~A} 1 \mathrm{E} 1$

November 25, 2003

Dear Ms. Cansick,

As per our conversation, I am writing to formally request the Auditor's reports for all communications companies who have been through and are going through an audit under the Employment Equity Act.

Please find a money order attached for $\$ 116.60$.

Thank you in advance for your assistance. Please do not hesitate to contact me at (416) 927-5301 should you have any questions.

Regards,

Audrey Wubbenhorst 
Appendix B: Ethics Review Application, Approval and Consent Forms

\author{
Research Ethics Board \\ Ryerson University
}

\title{
SUBMISSION OF A REQUEST FOR ETHICAL REVIEW:
}

Complete the following information, Items 1 to 12, required for Ethics Review of your Research Protocol Involving Human Subjects according to the Guidelines found at the same

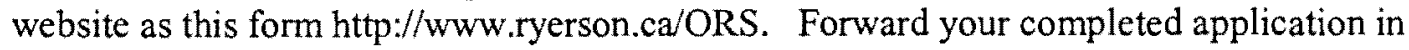
electronic form (preferred), or by mail to:

- The Chair of the Ethics Board, Dr. Robert Rinkoff, School of Early Childhood Education, rrinkoff@ryerson.ca, telephone 416-979-5000 ext.6332, and

- Alex Karabanow, Office of Research Services, akaraban@ryerson.ca telephone 416979-5000 ext.7112.

Your application should include:

AND

1. A completed application with all 12 items addressed and the Checklist filled out;

2. Completed consent forms for your human subjects;

3. Any questionnaires, survey forms or tests used in the protocol. and

If the above information is available electronically, please forward them in that form.

NOTE: Please allow a minimum of three weeks for the ethics review process; longer if your submission is not sent electronically.

1. Application Checklist This three-page form at the end, documents the research proposal title, names of investigators, project dates, funding source, type of data, type of subjects, and various other key information about the project. This checklist summarizes all of the information required and listed in more detail below. It serves as cover page and summary of the required information that needs to be filled out in detail under the following items:

2. Study Abstract In initial meetings with CEOs of Crown Corporations, Judge Abella concluded in her Royal Commission on Equality in Employment that it would be unfair for the federal government to impose employment equity legislation only on Crown corporations for the reason that it would put them at a competitive disadvantage. Therefore, the Employment Equity Act required that all federally regulated employers take steps to eliminate systemic discrimination.

Concentrating on the issue of corporate accountability, this paper will first evaluate the potential impact of the Employment Equity Act by analysing the key documents published prior to the Act. Secondly, it will evaluate the first manifestation of the Employment Equity Act in 1986 compared to its successor enacted in 1995.

The majority on the paper though will focus on case studies of companies in the communications industry. Through a review of audit reports and possible interviews with 
managers who liased with the auditors from those organization, I will assess how the revisions have impacted corporate compliance.

3.

Statement of Purpose and Background

Using Employment Equity reports filed by CHRC auditors and interviews with employees working for those companies, I will evaluate how the revised legislation has impacted the communications industry, which was largely self-regulated prior to 1995 . This method of analysis is significant in that no other research to date (to my knowledge) has utilized primary sources to gauge the Act's impact.

4. Subjects

a. Subject Characteristics. Ideally, I will be looking to interview one person from five communications companies governed by the Employment Equity Act for a total of five interview.

b. Selection Criteria. Potential interviewees must have been active in the Employment Equity Audit of their companies.

c. Recruitment Source. I will try and recruit subjects by telephoning the Human Resources offices companies. The script will be as follows: "I am a graduate students looking at the Employment Equity Act. I would like to speak to/contact the person(s) in your company who have direct accountability for ensuring compliance with this Act."

d. Informed Consent Process. I will make the initial contact with the subjects and will forward them consent forms via email.

e. Study Location. Most likely interviews will be taking place in corporate offices.

f. Potential Problems. It is possible that the individuals involved in the Employment Equity Audit may no longer be working for the companies.

5. Research Design and Methods

a. Research Design. Based on an analysis of the data submitted to HRDC by the company, I will formulate individual questions for the subjects.

b. Tests, Questionnaires, and Interview Guides. Interview schedule is to be determined. The only instrument being used will be a tape recorder.

c. Deception or Incomplete Disclosure. Not applicable.

6. Potential Benefits The subject will have access to my final paper which may help them in their work.

Risks: The risk involved is that the subject may reveal information, which is of a competitive nature. I will mitigate this risk by letting the subject know the information they provide to me may be circulated.

7. Costs Not applicable.

8. Compensation and Incentives Not applicable

9. Investigator Experience I am a graduate candidate in the M.A. Communication and Culture programme. My major research paper supervisor is Prof. John Shields.

10. Consent/Assent Forms Attached. 
11. Application Checklist for Ethics Review of Research Involving Human Subjects

\section{Human Ethics Review Board \\ Ryerson University}

REB: 2003-026

TITLE of the

RESEARCH

PROPOSAL: The Employment Equity Act and Corporate Accountability in the Communications Industry

Principal Investigator: Audrey Wubbenhorst (Communications and Culture)

E-mail Address: Audrey.wubbenhorst@bmo.com
Academic Title: Graduate Student

Telephone Number: (416) 927-5301

\section{Projected Dates of Data Collection and Analyses:}

Begin Recruitment Date: June 30 End Analysis Date: July 30

\section{Funding Source:}

a) Not funded/pending $X$

Funded

Sponsor
Active $\square$ (account

$\#$

Sponsor Reference \#

b) If the study is funded, will the Principal Investigator require the approval of the sponsor(s) before

Yes publication of the findings? No

If yes, please explain

c) Does the Principal Investigator(s) or Co-Investigator(s) have a financial interest or personal relationship with member(s) of the funding sponsor(s)?

No $\square \quad$ Yes

If yes, please state the nature of the relationship 
Will this study involve the use of existing data, documents, records, pathological specimens, or CHRC.

diagnostic specimens? No $\square \quad$ Yes $\mathrm{X}$-Publicly available documents released by

If yes, include a copy of your authorization to access this data, if the data are not publicly available.

Subjects to be recruited (Check all that apply):

Data will include (Check all that apply):

a) Adults (18+ years)

b) Children and minors (under 18)

a) Names of people

c) Cognitively impaired persons

b) Addresses

d) Prisoners

e) Elderly/aged persons

c) Telephone numbers

d) Age

f) Minorities

g) Students (describe)

h) Using existing data, no subjects will be recruited

e) Gender

f) Ethnicity

hi) Illiterate subjects

g) Marital Status

h) Income

j) Subjects whose primary language is not English

i) $\mathrm{SIN}$

j) Job Title

k) Employees or subordinates of the investigator

k) Names of Employers

1) Employees of institutions associated with the study

m) Other unique information-Specify

1) Types of Employers

Are codes used to link data to subjects? Yes $\square$ No $X$

Is compensation offered? Yes $\square \quad$ No $\mathrm{X}$

The Number of Subjects: 5

Method of recruiting (attach samples of posters/recruitment materials): Individual Letters

Will potential subjects be involved in:

a) an intervention or manipulation? Yes $\square$ No $X$

b) deception?

Yes $\square \quad$ No $X$

\section{You must acknowledge at least one of the risks below:}

\section{Potential Risk Exposures: Physical \\ Psychological $\square \quad$ Economic $\square$ Legal} Social

If you think your protocol is minimal risk to your subjects, state why you think it is minimal risk: The proposal is minimal risk because interviewees will be speaking about a topic they have professional experience in (the Employment Equity Act). Questions will be straightforward and may be sent in advance if requested.

Are there any issues of cultural diversity with respect to privacy that you are aware of in the questions 
you=re asking and the type of subjects you are recruiting?

No.

Instruments (submit a copy of all instruments to be used):
a) Standardized tests
b) Questionnaire
c) Interviews
d) Other (specify)

Data will be recorded by:
a) Written notes $X$
b) Audio tape $X$
c) Videotape/film
d) Photograph

Method of Instrument Administration:
a) in person (group) $\square$
b) in person (individual) $X$
c) telephone
$\mathrm{X}$
d) electronic mail
e) standard mail

Findings used for:

a) publication

b) evaluation

c) telephone

d) thesis/dissertation $X$

e) other (specific)

\section{Method of obtaining consent:}

$\mathrm{X}$ written consent form (include a copy)

$\square$ waiver or alteration of consent process (explain) 


\section{RYERSONUNIVERSTYY}

\section{Research Ethics Board}

To: Ms. Audrcy Wubbenhorst

Communications and Culture

From: Alexander Karabanow on behalf of Robert Rinkoff, Ph.D.

Chair, Research Ethics Board

c/o Early Childhood Education

Re: REB 2003 - 026: The Employment Fquity Act and Corporate Accountability in the Communications Industry

Date: July 16, 2003

Dear Ms. Wubbenhorst,

The review of your protocol REB File $\# 2003-026$ is now complete.

The project has becn approved for a one year period, subject to full REB ratification at the REB's next schcduled meeting. The study may proceed.

The approval may be extended after one year upon request.

Please note that REB approval pulicies require that you adhere strictly to the protocol as last reviewed by the REB and that any modifications must be approved by the Board before they can be implemented. Adverse or unexpected events must be reported to the REB as soon as possible with an indication from the Principal Investigator how these cvents a Tect, in the view of the Principal Investigator, the continuation of the protocol.

Finally, if rcscarch subjects are in the care of a health facility, at a school, or other institution or communiry organization, it is the responsibility of the Principal Investigator to ensure that the ethical guidelines and approvals of those facilities or institutions are obtained and filed with the REB prior to the initiation of any research protocols.

Please quote your REB file number (REB-2003-026) on future correspondence.

Congratulations and best of luck in conducting your research.

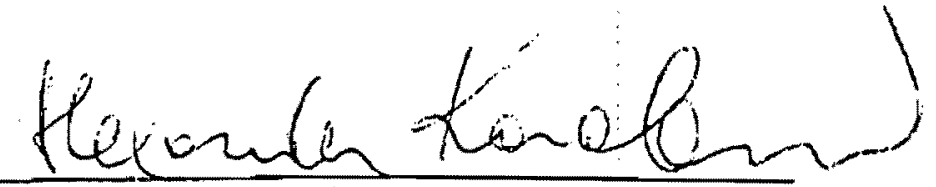

for Robert F. Rinkoff, Ph.D.

Chair, Research Ethics Board 


\section{Coasent Agreement}

\section{The Employment Equity Act and Corporate Accountability in the Communications Industry}

You are being asked to participate in a research sndy, which will result in a major research paper, part of the requirement for an M.A. in Cormunication and Culnure ar Ryetson Universiry. Before you give your consent to be a volunter, it is important that you read the following information and ask as many questions as necessary to be sure you understand what you will be asked to do.

Audrey Wubbenhorst, a graduate student in Communicarion and Culture will be interviewing you. Her tesearch is supervised by Prof. John Shields from Ryerson University.

In 1995, the Employment Equity Act was revised to include an Audit. Audrey is evaluating how the revised legislation has impacted the communicarions industry, which was largely self-regulated - as there was no Audit component - priar to 1995. The daca collected will not be anonymous. Some quotes collected may appear in the Major Research Paper. There is a potential risk that your commemary may be published and that you may be quoted as saying something you do not want to appear in the public domain. To mitigate this risk, if the smaty is to be published and you are quoted in it, Audrey will forward a draft to you. If you do not feel comfortable with the material, she will remove it.

The interview should take approximarely halt an hour to one hour and can take placc on the relophone. Either way. the interview will be tape recorded unless you prefer otherwise. It is likely that there will be some follow up questions sent to you either by phone or email. These tapes and email communication will be rerained at Audrey Wubbenhorst's residence until September 2004.

Panticipation in this sudy is voluntary. Your choice of whether or not to participate will not influence your future relations with Ryerson Univetsiny. If you decide to participate, you are free to withdraw your consent and to stop your participation at any time withour penalty or loss of benefits to which you are allowed.

At any paricular poim in the srudy, you may refuse to answer any particular question or stop participation altogether. You will be given the oppornnity to sccess to the general results of the sudy when available in the winter of 2004 . If you have any questions abour the research now, please ask. If you have questions later about the research, you may contact Audrey Wubbenhorst at (416) $927-5301$.

If you bave questions regarding your righrs as a human subject and participant in this sndy, you may contact the Ryerson University Research Ethics Board for information.

Research Ethics Board

c/o Office of Research Services, Ryerson University

Agreement:

350 Victoria Street, Toronto, ON MSB $2 \mathrm{~K} 3$

Your signanure below indicates that you have read the information in this agreement and have had a chance to ask any questions you have about the sudy. Your signature also indicates that you agree to be in the study and have been told that you can change your mind and withdraw your consent to panicipare at any time. You have been given a copy of this agreement.

You have been told that by signing this consen agreement you are not giving up any of your legal rights.

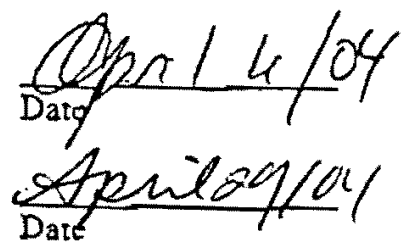




\section{Consent Agreement}

\section{The Emplnyment Equity Act and Corporate Accountablity in the Communications Industry}

You are being asked to participute in a research study, which will result in a major research paper, part of the requirement for an M.A. in Communication and Culture at Ryerson University. Before you give your consent to be a volunteer, it is important that you read the following information and ask as many questions as necessary to be sure you understand what you will be asked to do.

Audrey Wubbonhorst, a graduate student in Communication and Culture will be interviewing you. Her research is supervised by Prof. John Shields from Ryerson University.

Audrey is evaluating how the revised legislation has impacted the communications industry, which was largely selfregulated prior to 1995. The data collected will not be anonymous. Some quotes collected may appear in the Major Research Paper. There is a potential risk that your commentary may be published and that you may be quoted as saying something you do not want to appear in the public domain. To mitigate this risk, if the study is to be published and you are quoted in it, Audrey will forward a draft to you. If you do not feel comfortable with the material, she will remove it.

The interview should take approximately half an hour to one hour and can take place on the telephone. Either way. the interview will be tape recorded unless you prefer otherwise. It is likely that there will be some follow up questions sent to you either by phone or email. These tapes and email communication will be retained at Audrey Wubbenhorst's residence until September 2004.

Participation in this study is voluntary. Your choice of whether or not to participate will not influence your future relations with Ryerson University. If you decide to participate, you are free to withdraw your consent und to stop your participation at any time without penalty or loss of benefits to which you are allowed.

At any particular point in the study, you may refuse to answer any particular question or stop participation altogether. You will be given the opportunity to access to the general results of the study when available in the winter of 2004 . If you have any questions about the research now. please ask. If you have questions later about the research, you may contact Audrey Wubbenhorst at (416) 927-5301.

If you have questions regarding your rights as a human subject and participant in this study, you may contact the Ryerson University Research kthics Board for information.

\section{Research Ethics Board}

c/o Office of Research Services, Ryerson University

350 Victoria Street, Toronto, ON M5B 2 K3

\section{Agreement:}

Your signature below indicates that you have read the information in this agreement and have had a clance to ask any questions you have about the study. Your signature also indicutes that you agree to be in the study and have been told that you can change your mind and withdraw your consent to participate al any time. You have been given a copy of this agreement.

You have been wld that by signing this consent ageement you are not giving up any of your legal rights.

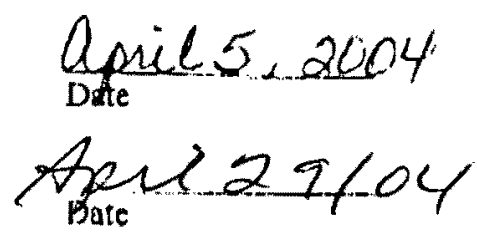




\section{Consent Agreement}

\section{The Employment Equity Act and Corporate Accountability in the Communications Industry}

You are being asked to participate in a research study, which will result in a major research paper, part of the requirement for an M.A. in Communication and Culture at Ryerson University. Before you give your consent to be a volunteer, it is important that you read the following information and ask as many questions as necessary to be sure you understand what you will be asked to do.

Audrey Wubbenhorst, a graduate student in Communication and Culture will be interviewing you. Her research is supervised by Prof. John Shields from Ryerson University.

Audrey is evaluating how the revised legislation has impacted the communications industry, which was largely selfregulated prior to 1995. The data collected will not be anonymous. Some quotes collected may appear in the Major Research Paper. There is a potential risk that your commentary may be published and that you may be quoted as saying something you do not want to appear in the public domain. To mitigate this risk, if the study is to be published and you are quoted in it. Audrey will forward a draft to you. If you do not feel comfortable with the material, she will remove it.

The interview should take approximately half an hour to one hour and can take place on the telephone. Either way, the interview will be lape recorded unless you prefer otherwise. It is likely that there will be some follow up questions sent to you either by phone or email. These tapes and email communication will be retained at Audrey Wubbenhorst's residence until September 2004.

Participation in this study is voluntary. Your choice of whelher or not 0 participate will not influence your future relations with Ryerson University. If you decide to participale, you are free to withdraw your consent and to stop your participation at any time without penalty or loss of benefits to which you are allowed.

At any particular point in the study, you may refuse to answer any particular question or stop participation altogether. You will be given the opportunity to access to the general results of the study when available in the winter of 2004 . If you have any questions about the research now, please ask. If you have questions later about the research, you may contact Audrey Wubbenhorst at (416) 927-5301.

If you have questions regarding your rights as a human subject and participant in this study, you may contact the Ryerson University Reseach Ethics Board for information.

Research Ethics Board clo Office of Research Services. Ryerson University 350 Victoria Street, Toronto, ON MSB 2K3

Agrement:

Your signature below indicates that you have read the information in this agreement and have had a chance to ask any questions you have about the study. Your signature also indicates that you agree to be in the study and have been told that you can change your mind and withdiaw your consent to participate at any time. You have been given a copy of this agreement.

You have been told that by signing this consent agreement you are not giving up any of your legal rights.

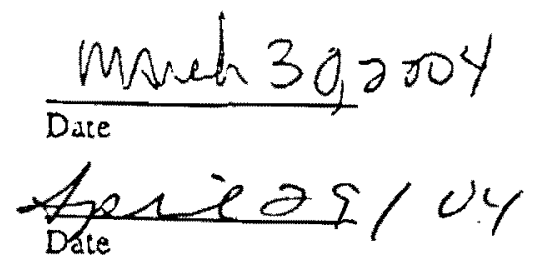




\section{Consent Agreement}

\section{The Employment Equity Act and Corporate Accountability in the Communications Industry}

You are being asked to participate in a research study, which will result in a major research paper, part of the requirement for an M.A. in Communication and Culture at Ryerson University. Before you give your consent to be a volunter, it is important that you read the following information and ask as many questions as necessary to be sure you understand what you will be asked to do.

Audrey Wubbenhorst, a graduate student in Communication and Culture will be interviewing you. Her research is supervised by Prof. John Shields from Ryerson University.

In 1995, the Employment Equity Act was revised to include an Audit. Audrey is evaluating how the revised legislation has impacted the communications industry. which was largely self-regulated - as there was no Audit component - prior to 1995. The data collected will not be anonymous. Some quotes collected may appear in the Major Research Paper. There is a potential risk that your commentary may be published and that you may be quoted as saying something you do not want to appear in the public domain. To mitigate this risk, if the study is to be published and you are quoted in it, Audrey will forward a draft to you. If you do not feel comfortable with the material, she will remove it.

The interview should take approximately half an hour to one hour and can take place on the telephone. Either way, the interview will be tape recorded unless you prefer otherwise. It is likely that there will be some follow up questions sent to you either by phone or email. These tapes and email communication will be retained at Audrey Wubbenhorst's residence until September 2004.

Participation in this sndy is voluntary. Your choice of whether or not to participate will not influence your future relations with Ryerson University. If you decide to participare, you are free to withdraw your consent and to stop your participation at any time without penalty or loss of benefits to which you are allowed.

At any paricular point in the study, you may refuse to answer any particular question or stop participation altngether. You will be given the opporrunity to access to the genetal zesults of the study when available in the winter of 2004. If you have any questions about the research now, please ask. If you have questions later about the research, you may contact Audrey Wubbenhorst at (416) 927-5301.

If you have questions regarding your rights as a human subject and participant in this study, you may conract the Ryerson University Research Ethics Board for information.

\section{Research Erhics Board}

c/o Office of Research Services, Ryerson University

350 Victoria Street, Toronto, ON MSB 2K3

Agreement:

Your signature below indicates that you have read the information in this agreement and have had a chance to ask any questions you have about the study. Your signature also indicates that you agree to be in the sndy and have been told that you can change your mind and withdraw your consent to participate at any time. You have been given a copy of this agreement.

You have been told that by signing this consent agreement you are not giving up any of your legal rights.

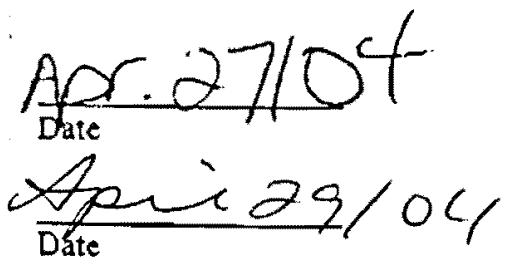

